\title{
Myth and Momentum: A Critique of Environmental Impact Assessments
}

\author{
Andrew J. Wright ${ }^{1,2 *}$, Sarah J. Dolman ${ }^{3}$, Michael Jasny ${ }^{4}$, E. C. M. Parsons ${ }^{2}$, Doris Schiedek ${ }^{1}$, \\ Sharon B. Young ${ }^{5}$ \\ ${ }^{1}$ Department of Bioscience, Aarhus University, Roskilde, Denmark; ${ }^{2}$ Department of Environmental Science and Policy, George Ma- \\ son University, Fairfax, USA; ${ }^{3}$ Whale and Dolphin Conservation, Chippenham, UK; ${ }^{4}$ Natural Resources Defense Council, Vancou- \\ ver, Canada; ${ }^{5}$ The Humane Society of the United States, Washington, USA. \\ Email: *marinebrit@gmail.com
}

Received June $8^{\text {th }}, 2013$; revised July $15^{\text {th }}, 2013$; accepted August $12^{\text {th }}, 2013$

Copyright (c) 2013 Andrew J. Wright et al. This is an open access article distributed under the Creative Commons Attribution License, which permits unrestricted use, distribution, and reproduction in any medium, provided the original work is properly cited.

\begin{abstract}
Environmental Impact Assessments (EIAs) are designed to evaluate all reasonably foreseeable environmental consequences of human activities. Appropriate governmental scientists traditionally produced EIAs for management agencies in many countries. However, many EIAs are now contracted out, often to the lowest bidder without due consideration of expertise. Others suffer from limited agency resources. Consequently, many EIAs have become insufficiently researched documents that draw heavily from previous EIAs while being rushed to completion to meet legislative deadlines or avoid delaying projects. Habitual treatment of topics often ignores recent scientific literature, perpetuating previous misconceptions and analytical flaws. Common problems in EIAs discussing wildlife include: a focus on lethal takes, with little consideration of non-lethal impacts or habitat degradation; a general dismissal of the possibility that non-significant (to the resource) impacts can, when combined, become significant; and the assumption that behavioral habituation in animals represents an end of impact. Incentive to break the cycle is somewhat lacking in this now often commercially competitive environment, where contracts are increasingly awarded by industry, generating potential conflict of interest. We believe investment in thorough, impartially written, scientifically-based and up-to-date EIAs is important for appropriately representing and managing ecosystems and their resources and avoiding potentially expensive litigation.
\end{abstract}

Keywords: Policy; Management; Environmental Impact Assessment; Errors; Cumulative Impact Assessment

\section{Introduction}

Under various legal names, Environmental Impact Assessments (EIAs) are used around the world as management tools for assessing the types and extent of environmental impact likely to be caused by a given human action or activity on a species, habitat or ecosystem (and sometimes also the human environment). Frequently, they must also include cumulative impacts assessments (CIAs), which consider impacts of ancillary activities (e.g., the construction and prolonged presence of a road leading to the facility to be build) and often also other reasonably foreseeable future activities, that may or may not be directly associated with the project (e.g., the urban development of the local area along the road to the facility). Whether purely informative tools or backed by leg-

\footnotetext{
"Corresponding author.
}

islative requirements to select (or even reject) the least impactful option, EIAs need to be conducted early enough in planning stages that financial commitments have not been made and the project can be changed if needed. In accordance with various guidance (e.g., [1]) EIAs are intended to guide environmentally responsible management practice through an impartial, objective, scientifically-based, thorough, comprehensive and up-todate description and discussion of: the baseline environment; current, planned and potential human activities; and the expected impacts of these activities individually and cumulatively. In this sense, EIAs are an important element of the rational decision making process for authorities and environmental managers.

However, EIAs often fall short of this ideal for various reasons (e.g., [2,3]). In even the best circumstances the full extent of many of the impacts of human activities are 
not completely known or understood. Similarly, the human activity may result in impacts that can interact in unpredictable ways to generate synergistic or antagonistic impacts, which can be greater or smaller than the sum of their parts. Furthermore, many standards written into law are ill- or un-defined, especially within a scientific context (see discussion in [4]). These problems are unavoidable obstacles for authors of EIAs, however documents that nonetheless incorporate the best available relevant knowledge and information will still provide management agencies with a tool to bound uncertainties, make appropriate decisions and to guide allocation of funding to fill data gaps. Regardless, it is possible (and desirable) to incorporate precautionary discussions to encapsulate at least some of this uncertainty into EIAs, although this practice is unfortunately not commonplace.

More problematic is when EIAs do not reach their intended potential due to more tractable issues. Despite the existence of regulations and guidelines mandating timeframes, minimums of included information and internal or public document reviews, many EIAs now suffer from an investment of insufficient time, funding, expertise and/or attention to detail. Many of the resulting issues have been noted before (e.g., [2,3]). However, little progress has been made. Some EIAs are even little more than exercises in copy-pasting, with some astonishingly obvious flaws that have passed through review processes, or if they were identified have remained unchanged and, on occasion, have even repeated at a later time.

In the following we try to illustrate some of the potential shortcomings of EIAs produced under the circumstances described above. To do this, we focus on a few specific examples from our combined experience to make our points, as we feel this is more revealing than a simple count of each type of issue following an extensive review of EIAs. This represents an attempt to raise awareness of the problems among scientist and policy practitioners, with a view to improving assessment and ultimately conservation, rather than an effort to single out any specific consulting companies whose reports we used for the various examples. Therefore, the references and some of the specific project details from assessments produced by private companies used in the examples below have been withheld. These details were, however, provided to the Editor at the time of submission. Examples from documents produced by government agencies have been provided intact as they do not have a financial stake in their reports. Accordingly, we attempted to focus on available, government-produced documents, where possible, for better reader access.

\section{Defining the Problem}

Expertise can be expensive, but management agencies, especially at times of financial crisis, operate under restricted budgets. This results in underfunding of the preparation of these management tools. EIAs, especially when their production or review is delayed by budget, can also be seen as obstructive to industrial development and thus also financial growth. In fact, partly as a consequence of heavy lobbying by industry, there are (at time of writing) a number of bills currently under consideration in Congress that would exempt various projects or types of activities from the EIA requirements of US national legislation. The level of expertise or the total time invested in an EIA may thus be reduced, resulting in an inferior product.

Many EIAs are also now prepared outside governmental agencies. This, in principle, is not a problem, but the contracting company should have appropriate expertise and be able to devote the necessary resources to the production of the EIA. There are, in fact, many good quality EIAs that have been produced in this manner. However, EIAs are now often contracted to the lowest bidder, with a focus often more on achieving mandated deadlines, rather than on product quality. In some cases, more expertise and resources may be put into winning a contract than completing it, with the important scientific work being done cheaply by newly graduated bachelor's degree holders or inexperienced interns. This often results in the practice of "cutting and pasting" old or inappropriate information from previous EIAs on similar projects. Some EIAs are even conducted (or contracted) by the company intending to conduct the activity, bringing in the potential for bias arising from conflicts of interest in addition to financially-based concerns (including the potential for winning future contracts).

To demonstrate some of the results of these issues, we offer the following examples:

1) The Steller Sea Lion and Northern Fur Seal Research: Final Programmatic Environmental Impact Statement produced by the US National Marine Fisheries Service (NMFS) [5]. This analysis was written by and/or based on analysis provided by many of the very same scientists whose activities were being assessed. The consequences included, but were not limited to:

a) An assessment of the number of takes (behavioral disturbance, harassment, injury and death) that was complicated, convoluted and highly subjective. In fact, a subsequent implementation report by NMFS [6] noted that there was "little quantitative information on the effects of most research activities" and that they are instead based conclusions on "anecdotal observations and professional opinions of researchers at NMML”. The US National Marine Mammal Laboratory (NMML) is a branch of NMFS and the recipient of a sizable research permit under the project that ultimately went ahead. The document also criticizes such practice, noting that "an 
approach where individuals monitor their own impacts lacks independence" and that "NMFS researchers would be in a conflict of interest situation reviewing their own planned work" [6].

b) The total number of takes reported often did not match the actual total presented in the EIA, if all the items were added together and/or did not agree with estimates published elsewhere. Regardless of these errors, the final EIS still reported a research-related mortality rate that was considered to be "major", without considering the added takes of native hunting and fisheries-related mortality or other impacts cumulatively for the endangered population.

c) There was no assessment of the cumulative or synergistic consequences for the animals of conducting multiple, often invasive, procedures on individual animals.

d) The production of information of arguably little value (see the thorough critique of the resulting program by Berman [7]), especially with regards to the conservation goals that had been identified for the species.

2) The US Minerals Management Service (MMS) Chukchi Sea Planning Area Oil and Gas Lease Sale 193 and Seismic-Surveying Activities in the Chukchi Sea Final Environmental Impact Statement [8]. Despite mounting evidence over the last few decades that impacts can continue despite behavioural "habituation", this EIA (like many others) reported "habituation" as the end of impact. Specifically, they implied that bowhead whale (Balaena mysticetus) disturbance and potential displacement would reduce as it was habituated to the noise, resulting in only temporary impacts.

3) The MMS Environmental Assessment: Proposed OCS Lease Sale 190, Central Gulf of Mexico [9]. After mentioning the potential for stress-related impact several times they reached a "Finding of No Significant Impact (FONSI)" without actually discussing how they considered these effects. Of particular note is the statement, "Chronic sublethal effects (e.g., stress) resulting in persistent physiological or behavioral changes and/or avoidance of impacted areas could cause declines in survival or fecundity, and population; however, such declines are not expected", with no further explanation attached. This EA is also a very good example of copy-and-paste behavior as much text is repeated verbatim from the associated Environmental Impact Statement from an earlier lease sale [10]. It has also been repeated in various documents since, with little consideration for new information (e.g., [11]).

4) The UK Department of Energy and Climate Change assessment reports under the Conservation of Habitats Regulations for the Block 17/4B 2D Seismic Survey [12] and the Braemore, Forse, Berriedale and Helmsdale Prospects and Burrigill site survey [13]. These reassure the reader that all proposed seismic surveys will be re- quired to follow the UK's Joint Nature Conservation Committee (JNCC) Guidelines for Minimizing the Risk of Injury and Disturbance to Marine Mammals from Seismic Surveys "in order to ensure that there are no marine mammals within the range that could result in auditory physical impact” [14]. However, earlier versions of these (and other) mitigation guidelines have been widely criticized for their sweeping 'common sense' assumptions, which have little scientific basis, and their questionable efficiency (e.g., $[15,16])$. The guidelines lack of scientific basis has even been admitted elsewhere by the UK government [17].

5) The report by one company regarding their spill management plan for the Gulf of Mexico [citation withheld]. This report was filed and accepted with errors and omissions. Perhaps the most obvious of these was the placing of walrus and "population concentration areas" of sea otters in the Gulf of Mexico. This was clearly a situation where an informed consideration of the baseline information was replaced with an exercise in copying and pasting.

6) One EIA prepared in relation to planned mining activities in Northeast Greenland [citation withheld] the occurrence of deer is described which are not present in the area of discussion. Although these particular examples (5 \& 6) are somewhat amusing, such whole-sale lifting of text is inherently dismissive of new information, especially when companies are not even copying from their most recent documents. This will lead to various failings when done less obviously, such as using outdated distributions, not properly accounting for the extent of impact, or under-assessing the sensitivity of a species, habitat or ecosystem. It will also perpetuate any of the above-mentioned errors.

7) One document discussing the development of an offshore renewable energy facility in Scotland made only a token gesture at a required CIA. This may possibly have been because a thorough assessment would have been too time-consuming and expensive. In any case, the very basis of such CIAs is that otherwise negligible impacts can accumulate or interact to become biologically significant when faced by animals or populations consecutively or concurrently. However, this report openly stated that, “ $\ldots$ it is considered very unlikely that significant cumulative effects will arise when they are considering individual impacts that are themselves not significant". Such effects were then excluded from the CIA. This thinking is completely inconsistent with legal requirements and is certainly not considered best practice.

\section{Possible Solutions-The Way Forward}

To remedy many of these issues, managers and authorities must accept that faster and/or cheaper EIAs are not 
always better EIAs. Instead, such cut-price EIAs are often incomplete, not very thorough and lacking current scientific knowledge. Managers and authorities must consider appropriate expertise (not simply documented by having produced EIAs before) when assigning contracts. Any possible conflicts of interest need to be avoided where possible or otherwise stated explicitly. In fact, EIA processes would benefit from the inclusion of a formalized external review or audit to specifically address the various possible failings. One further alternative is that EIAs could be contracted out by a neutral third person (e.g. an overseeing agency), with the costs still allocated to the developer.

Similarly, documents containing a comprehensive description of the physical and biological components of the ecosystem(s), along with the identification of biological important or sensitive areas and periods and a review of current human activities and impacts, could be (and in some cases already are being) prepared for specific regions where much development is expected. Such documents should be initiated and funded by the authorities and could then form a basis to draw upon when preparing more specific project-based impact assessments. Some such elements can already be found in the Strategic Environmental Impact Assessments (SEIAs) that form a part of the licensing process and political approval for both mining and hydrocarbon exploration activities in Greenland, which are usually prepared on behalf of the Greenland government (e.g., [18,19]). Similar reviews might also be of great benefit to integrated coastal planning.

The annual marine mammal stock assessment reports, which are mandated reports on the status of marine mammal populations in the US, could also be extended to serve this function. It can even be argued that they should already be including such information. Regardless, it is extremely important that such documents be revised frequently to avoid the information contained within becoming outdated.

However, all of these remedies are meaningless if management agencies do not, for whatever reason, heed the information within EIAs, or adhere to the legallyestablished thresholds and standards that EIA conclusions may, depending on the country and specific situation, be associated with. For example, the Steller sea lion research program went ahead at the initially proposed level, despite levels of take that exceeded suggested thresholds presented within the EIA. Furthermore, when research-related mortality of sea lions in a captive research program exceeded the permitted rate, NMFS simply issued the researchers with an increase in their authorized mortalities, instead of, perhaps more appropriately, requiring a substantial modification to the research practices.
Another example can be found in the US Navy Overseas Environmental Impact Statement and Environmental Impact Statement for Surveillance Towed Array Sensor System Low Frequency Active (SURTASS LFA) Sonar [20] and related rulemaking [21]. In this case, NMFS, in assessing the Navy's activities, limited cumulative impacts by setting an annual take limit of $12 \%$ for any individual species or population, but then proceeded to authorize the Navy for annual takes of up to $18 \%$ for any given population. Again, appropriate modifications to practices, including the requirement for additional mitigation measures, were not put into place, simply because NMFS did not follow their own advice. Such outcomes might be reduced through increased levels of official accountability.

\section{Conclusions}

We acknowledge that financial constraints are real logistical challenges and that workloads are continually increasing, partly as scientific research reveals ever-more complex relationships between human activities and their consequences (e.g., chemical or noise pollution) and the impacts on animals, species or habitats. However, efforts should be made to maintain the highest quality EIAs and official EIA reviews to avoid these management tools from simply becoming little more than an administrative exercise.

The fact is that there are many thorough, well-documented EIAs being produced every year, despite the current economic climate. We strongly advocate that the high standards of EIA production and official review behind this subset be much more widely applied than is currently the case. This can be facilitated in many ways, including through the use of truly strategic assessments (not just those labeled as such), the allocation of sufficient time (including through early planning and engagement) and resources (including enough appropriate expertise), consideration of all the appropriate information, and consistency in decision-making. Higher standards would increase the credibility of not only the regulatory agencies, but of the whole EIA process, both within the scientific community and also the broader public. Such credibility is an important consideration for documents that can, on occasion, become center-pieces of politically-charged controversies and/or expensive, prolonged litigation.

Our security and well-being is closely tied to the health of our environment [22]. We believe that this places informed environmental stewardship beyond compromise.

\section{Acknowledgements}

We thank the anonymous reviewers for their helpful comments, which improved the manuscript. This manu- 
script received no specific grant from any funding agency, or commercial or not-for-profit sectors. However, all authors have a professional interest in appropriate environmental protection and mitigation for anthropogenic activities.

\section{REFERENCES}

[1] International Association for Impact Assessment, "Principles of Environmental Impact Assessment Best Practise,” IAIA, Fargo, North Dakota, 1999, 4 p.

[2] K. Chapman, "Issues in Environmental Impact Assessment," Progress in Human Geography, Vol. 5, No. 2, 1981, pp. 190-210. doi:10.1177/030913258100500202

[3] C. H. Peterson, "Improvement of Environmental Impact Analysis by Application of Principles Derived from Manipulative Ecology: Lessons from Coastal Marine Case Histories,” Australian Journal of Ecology, Vol. 18, No. 1, 1993, pp. 21-52. doi:10.1111/j.1442-9993.1993.tb00433.x

[4] F. Gosselin, "Management on the Basis of the Best Scientific Data or Integration of Ecological Research within Management? Lessons Learned from the Northern Spotted Owl Saga on the Connection between Research and Management in Conservation Biology," Biodiversity Conservation, Vol. 18, No. 4, 2009, pp. 777-793. doi:10.1007/s10531-008-9449-6

[5] US National Marine Fisheries Service, "Steller Sea Lion and Northern Fur Seal Research: Final Programmatic Environmental Impact Statement, Volume 1,” US Department of Commerce, National Oceanic and Atmospheric Administration, NMFS, Office of Protective Resources, Permits Division, Silver Spring, Maryland, 2007. http://www.nmfs.noaa.gov/pr/pdfs/permits/eis/fpeis.pdf

[6] US National Marine Fisheries Service, "National Marine Fisheries Service Policy and Guidance for Implementation of the Steller Sea Lion and Northern Fur Seal Research Permits and Grants Programs under the Preferred Alternative of the 2007 Final Programmatic EIS,” US Department of Commerce, National Oceanic and Atmospheric Administration, NMFS, Office of Protective Resources, Permits Division, Silver Spring, Maryland, 2008. http://www.nmfs.noaa.gov/pr/pdfs/permits/ssl_eis_policy. pdf

[7] M. Berman, "Endangered Species, Threatened Fisheries: Science to the Rescue! Evaluating the Congressionally Designated Steller Sea Lion Research Program,” Marine Policy, Vol. 32, No. 4, 2008, pp. 580-591. doi:10.1016/j.marpol.2007.10.007

[8] US Minerals Management Service, "Chukchi Sea Planning Area Oil and Gas Lease Sale 193 and Seismic-Surveying Activities in the Chukchi Sea. Final Environmental Impact Statement," OCS EIS/EA MMS 2007-026. US Department of the Interior, Minerals Management Service, Alaska OCS Region Anchorage, Alaska, 2007. http://www.alaska.boemre.gov/ref/EIS\%20EA/Chukchi_ FEIS_193/LS\%20193\%20FEIS\%20Vol\%20I.pdf

[9] US Minerals Management Service, "Environmental Assessment: Proposed OCS Lease Sale 190, Central Gulf of
Mexico,” OCS EIS/EA MMS 2003-066. US Dept. of the Interior, Minerals Management Service, Gulf of Mexico OCS Region, New Orleans, Louisiana, 2003. http://www.gomr.boemre.gov/PDFs/2003/2003-066.pdf

[10] US Minerals Management Service, “Gulf of Mexico OCS Oil and Gas Lease Sales: 2003-2005; Central Planning Area Sales 185, 190, 194, 198, and 201; Western Planning Area Sales 187, 192, 196, and 200-Final Environmental Impact Statement,” OCS EIS/EA MMS 2002-052. US Dept. of the Interior, Minerals Management Service, Gulf of Mexico OCS Region, New Orleans, Louisiana, 2002.

http://www.gomr.boemre.gov/homepg/regulate/environ/n epa/CW/Vol\%201/Central\%20-\%20Western\%20Final\%2 0EIS\%20Vol\%201.pdf

[11] US Minerals Management Service, "Environmental Assessment: Proposed OCS Lease Sale 196, Western Gulf of Mexico," OCS EIS/EA MMS 2005-010. US Dept. of the Interior, Minerals Management Service, Gulf of Mexico OCS Region, New Orleans, Louisiana, 2005. http://www.gomr.boemre.gov/PDFs/2005/2005-010.pdf

[12] UK Department of Energy and Climate Change, "Record of the Appropriate Assessment Undertaken Under Regulation 5 of the Offshore Petroleum Activities (Conservation of Habitats) Regulations 2001 (As Amended). April 2011. Title of Application: Block 17/4B 2D Seismic Survey,” DECC, 2011.

[13] UK Department of Energy and Climate Change, "Record of the Appropriate Assessment Undertaken Under Regulation 5 of the Offshore Petroleum Activites (Conservation of Habitats) Regulations 2001 (As Amended). April 2011. Title of Application: Seismic Survey Programme, Braemore, Forse, Berriedale and Helmsdale Prospects and Burrigill Site Survey,” DECC, 2011.

[14] UK Joint Nature Conservation Committee, “JNCC Guidelines for Minimising the Risk of Injury and Disturbance to Marine Mammals from Seismic Surveys,” JNCC, Aberdeen, 2010.

http://jncc.defra.gov.uk/pdf/JNCC_Guidelines_Seismic\% 20Guidelines_August\%202010.pdf

[15] C. R. Weir and S. J. Dolman, "Comparative Review of the Regional Marine Mammal Mitigation Guidelines Implemented during Industrial Seismic Surveys, and Guidance towards a Worldwide Standard,” Journal of International Wildlife Law and Policy, Vol. 10, No. 1, 2007, pp. 1-27. doi:10.1080/13880290701229838

[16] E. C. M. Parsons, S. Dolman, M. Jasny, N. A. Rose, M. P. Simmonds and A. J. Wright, "A Critique of the UK's JNCC Seismic Survey Guidelines for Minimizing Acoustic Disturbance to Marine Mammals: Best Practice?” Marine Pollution Bulletin, Vol. 58, No. 5, 2009, pp. 643-651. doi:10.1016/j.marpolbul.2009.02.024

[17] UK Department of Trade and Industry, "Strategic Environmental Assessment of Parts of the Central and Southern North Sea SEA 3,” DTI, 2002. http://www.offshore-sea.org.uk/consultations/SEA_3/SE A3_Assessment_Document_Rev1_W.pdf

[18] A. Mosbech, D. Boertmann and M. Jespersen, "Strategic Environmental Impact Assessment of hydrocarbon activi- 
ties in the Disko West area,” Report No. 618, National Environmental Research Institute (NERI), University of Aarhus, Roskilde, 2007.

[19] D. Boertmann and A. Mosbech, "Eastern Baffin Bay-A Strategic Environmental Impact Assessment of Hydrocarbon Activities,” Aarhus University, DCE-Danish Centre for Environment and Energy, Scientific Report from DCE-Danish Centre for Environment and Energy, No. 9, 2011, 270 p.

[20] US Department of the Navy, "Final Overseas Environmental Impact Statement and Environmental Impact Statement for Surveillance Towed Array Sensor System
Low Frequency Active (SURTASS LFA) Sonar System: Volume I," US Department of the Navy, Arlington, Virginia, 2001, $688 \mathrm{p}$.

[21] US National Marine Fisheries Service, “Taking Marine Mammals Incidental to Navy Operations of Surveillance Towed Array Sensor System Low Frequency Active Sonar,” Federal Register, Vol. 67, 2002, pp. 46712-46789.

[22] Millennium Ecosystem Assessment, "Ecosystems and Human Well-Being: Biodiversity Synthesis,” World Resources Institute, Washington, D.C., 2005.

http://www.maweb.org/documents/document.354.aspx.pd $\mathrm{f}$ 